\title{
BMJ Global Health Is female genital mutilation/cutting associated with adverse mental health consequences? A systematic review of the evidence
}

To cite: Abdalla SM, Galea S. Is female genital mutilation/ cutting associated with adverse mental health consequences? A systematic review of the evidence. BMJ Global Health 2019;4:e001553. doi:10.1136/ bmjgh-2019-001553

Handling editor Seye Abimbola

- Additional material is published online only. To view please visit the journal online (http://dx.doi.org/10.1136/ bmjgh-2019-001553).

Received 13 March 2019 Revised 30 May 2019 Accepted 15 June 2019

\section{Check for updates}

(C) Author(s) (or their employer(s)) 2019. Re-use permitted under CC BY-NC. No commercial re-use. See rights and permissions. Published by BMJ.

Epidemology, Boston University School of Public Health, Boston, Massachusetts, USA

Correspondence to Dr Salma M Abdalla; abdallas@bu.edu

\section{ABSTRACT}

Introduction The adverse physical consequences of female genital mutilation/cutting (FGM/C) have been thoroughly investigated and documented. Yet, we know little about the adverse mental health consequences of the practice. To fill this research gap, we systematically reviewed studies that assessed any adverse mental health consequences related to $\mathrm{FGM} / \mathrm{C}$.

Methods We searched four databases from inception to 21 December 2018. We then reviewed all titles and abstracts for relevant studies. We used the National Institutes of Health quality assessment tool to appraise the quality of each study and the Newcastle-Ottawa Scale to rate the risk of bias within studies.

Results We included 16 studies in this review; only six studies examined the association between $\mathrm{FGM} / \mathrm{C}$ and adverse mental health outcomes as the sole research question. Among the included studies, 10 were conducted at the participants' country of origin. The sample size of the populations studied ranged from 3 to 4800 participants. Only one study received a rating of 'good' methodological quality.

Fourteen of the 16 studies reported an association between $\mathrm{FGM} / \mathrm{C}$ and at least adverse mental health outcome. These included eight studies that reported a higher burden of adverse mental health outcomes among women who underwent FGM compared with women who did not undergo FGM/C. Four studies reported a correlation between the severity of FGM/C and the severity of adverse mental health outcomes.

Conclusion This systematic review documents an association between FGM/C and adverse mental health outcomes. Importantly, our review demonstrates the need for more rigorous research on the topic.

\section{INTRODUCTION}

The total number of women and girls who have undergone female genital mutilation/ cutting (FGM/C) is unknown. However, the United Nations International Children's Emergency Fund estimates that there are currently more than 200 million women and girls who have undergone FGM/C, living in 30 countries around the globe. ${ }^{1}$ Moreover, while

\section{Key questions}

What is already known?

- There are more than 200 million women and girls who have undergone female genital mutilation/cutting $(\mathrm{FGM} / \mathrm{C})$, living in 30 countries around the globe Further, about 3 million girls remain at risk of being subjected to FGM/C annually.

- There has been an increased interest in studying the adverse health outcomes associated with FGM/C over the past few decades. The adverse physica consequences of $\mathrm{FGM} / \mathrm{C}$ have been thoroughly investigated and documented. We know, however, very little about the adverse mental health consequence of the practice.

- Despite poor mental health being cited as a consequence of the practice in most reports on $\mathrm{FGM} / \mathrm{C}$, data documenting the prevalence and severity of such consequences are sparse.

What are the new findings?

- The quality of the studies assessed is generally weak.

- Our systematic review documents an association between FGM/C (especially among severe cases of $\mathrm{FGM} / \mathrm{C}$ ) and adverse mental health outcomes.

What do the new findings imply?

- Future work should create more rigorous evidence, particularly on the correlation between FGM/C type and severity of adverse mental health outcomes.

the overall rate of the practice is declining, about 3 million girls remain at risk of being subjected to FGM/C annually. ${ }^{23}$ The practice is most prevalent in Eastern, Northeastern, Western regions of Africa, a number of countries in the Middle east and Asia, and asylum seekers and migrant communities from these countries-mainly to high-income countries. $^{45}$

FGM/C refers to any practice that involves deliberately cutting, injuring or changing the external female genitalia. As such, the FGM/C ranges from ritual superficial nicks to 
the complete removal of the external genitalia. FGM/C is often performed for cultural, religious or other non-medical reasons; often on girls between the ages of 4 and $10 .{ }^{67}$ WHO identifies four types of FGM/C based on the procedure and severity; type III being the most severe. ${ }^{8}$ There is a near global consensus for the need to protect girls from undergoing FGM/C, evidenced by the fact that FGM/C is illegal in most countries. ${ }^{39}$ Moreover, the practice is considered a violation of the international human rights laws. ${ }^{5}$ A number of international agencies and government have recently been advocating for investing in the provision of adequate care to address the health-related consequences of FGM/C. ${ }^{5}$

Over the past few decades, there has been an increased interest in studying the adverse health outcomes associated with $\mathrm{FGM} / \mathrm{C}$. The adverse physical consequences of $\mathrm{FGM} / \mathrm{C}$ have been thoroughly investigated and documented. ${ }^{10-13}$ We know, however, very little about the adverse mental health consequence of the practice. Despite poor mental health plausibly being a potential consequence of FGM/C, data accurately documenting such outcomes are sparse. Prior efforts to examine the state of the evidence on adverse mental health outcomes were often non-systematic in their approach or only reported mental health disorders in conjunction with sexual health-related outcomes of women who underwent FGM/C. ${ }^{14-16}$ To our knowledge, to date, there has been no systematic effort to synthesise the evidence that examines the adverse mental health outcomes associated with FGM/C in the public health or medical literature.

To fill this research gap, we systematically reviewed studies that assessed any adverse mental health consequences related to FGM/C. This review aimed to answer the question: what are the psychological disorders associated with undergoing FGM/C?

\section{METHODS}

\section{Search strategy}

We conducted a search across the following bibliographic databases: PubMed, ${ }^{17}$ Embase, ${ }^{18}$ Web of Science ${ }^{19}$ and PsycINFO $^{20}$ from inception to 21 December 2018. We present the detailed search strategies in online supplementary file 1 . Overall, we combined various synonyms for FGM/C with terms focusing on mental health outcomes including various synonyms for mental health, depression, anxiety and post-traumatic stress disorder (PTSD). To maximise the number of studies identified, we applied no filters (except for a filter limiting the sex of participants to female in PsycINFO database). We also conducted a manual search of the references of included studies from the database search and prior reviews on the FGM/C to account for any records we might have missed.

\section{Study identification and abstraction}

Following deduplication using the reference management software Mendeley, we screened the titles and abstracts of identified records to decide whether we

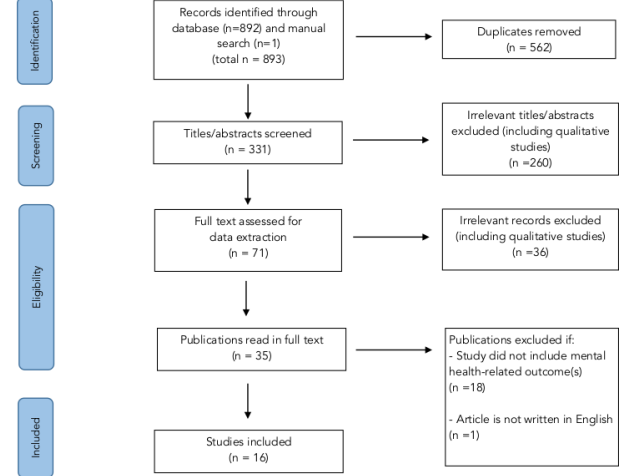

Figure 1 Flow chart describing the study selection process and number of articles retrieved, included and excluded.

should appraise the full paper using the systematic reviews web app Rayyan QCRI. We then screened full texts to determine whether to include or exclude articles. We excluded articles if the study was qualitative in nature, did not report psychological outcome(s), or if the full text was not written in English.

We abstracted included studies into an electronic form (Microsoft Excel). In the abstraction form, we summarised the research question(s), study population and sample size, psychological outcomes investigated, tools used for psychological assessment and study results. We present a flow chart, guided by the Preferred Reporting Items for Systematic Reviews and Meta-Analyses guidelines, describing the study selection process and number of articles retrieved, included and excluded in figure 1.

\section{Study quality assessment and risk of bias}

No study was excluded from this review on the basis of methodological quality. We did, however, use the US Department of Health and Human Services, National Institutes of Health quality assessment tool for observational cohort and cross-sectional studies to appraise and report on the quality of each study. ${ }^{21}$ The answers to the tool measures were 'yes', 'no', 'not mentioned' or 'not relevant'. We then rated the studies as of 'poor', 'fair' or 'good' methodological quality.

Guided by the Newcastle-Ottawa Scale for risk assessment of non-randomised trials, we then assessed the risk of bias for each of the included studies. We assessed each study on risk of bias in participant selection (representativeness, size and non-respondents to study sample), comparability (reporting on different exposure groups) and exposure/outcome relationship measurement (quality of outcome assessment methods and appropriateness of statistical methods used for analysis). ${ }^{22} 23$ For each study, we then rated levels of risk as 'low level of risk', 'high level of risk' and 'unclear risk'. The last category indicates that the information needed for adequate assessment was inconclusive or unavailable.

\section{Patient and public Involvement}

Patients were not involved in conducting this review. 


\section{RESULTS}

We describe the research questions, study population and sample size, mental health outcomes investigated, tools used for psychological assessment, key results and methodological quality of the 16 studies included in this review in detail in table 1.

\section{Research questions}

Of the 16 studies we included, six focused solely on the adverse mental outcomes of FGM/C. ${ }^{74-28}$ The other 10 studies examined a variety of FGM/C-related health measures, including adverse mental health outcomes. ${ }^{29-38}$

\section{Study population and sample size}

Studies varied in both characteristics of populations studied and sample size. While a number of studies restricted their populations to a specific ethnic group or age category, others included a wide range of demographic characteristics. Ten studies were conducted at the participants' country of origin: Egypt, Ethiopia, Iran, Iraq, Israel, Kuwait and Senegal ${ }^{724-27} 30-323435$ and six studies targeted migrant women in Greece, the Netherlands, Spain and the USA. ${ }^{28} 2936$ 36-38 Seven studies examined potential adverse mental health outcomes spanning adolescence and adulthood, ${ }^{7} 27$ 30-32 3438 six studies restricted their populations to adults, ${ }^{25} 2829333637$ two studies to adolescents ${ }^{24}{ }^{26}$ and one study ${ }^{35}$ did not list participants' age range. While the majority of studies focused on recruiting women, one study ${ }^{35}$ recruited couples. The sample size of populations studied ranged from 3 to 4800 participants.

\section{Study design}

All studies were cross-sectional in nature and did not follow participants over time. Eleven studies used comparison groups of women who did not undergo

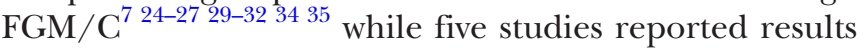
only from women who underwent FGM/C. ${ }^{2833} 36-38$

\section{Measurement of adverse mental health outcomes}

Studies used a variety of instruments for psychological assessment. Four studies used the Hopkins symptoms check list 25 (SCL 25) to assess the burden of depression and anxiety. ${ }^{28} 28377$ Three studies used the SCL 90 to assess the burden of somatisation, depression, anxiety, hostility and phobia. ${ }^{24} 2532$ Three studies used the mini international neuropsychiatric interview to assess either the burden of PTSD, affective disorder, anxiety ${ }^{730}$ or the burden of depression. ${ }^{37}$ Two studies used the General Health Questionnaire-28 item to assess the burden of somatic symptoms, insomnia, social dysfunction and depression. ${ }^{31} 34$ Two studies used the Harvard Trauma Questionnaire-30 item to assess the burden of PTSD. ${ }^{28} 37$

Instruments used in one study to assess the burden of PTSD included the PTSD CheckList-Civilian Version, ${ }^{29}$ PTSD Inventory ${ }^{25}$ Arabic version of Child PTSD Reaction Index $^{26}$ and PTSD Symptom Scale-Interview. ${ }^{28}$ Instruments used in one study to assess the burden of depression included the Center for Epidemiologic
Studies Depression Scale ${ }^{29}$ and the Arabic version of the Children's Depression Index. ${ }^{26}$ One study used the SCL-25 to assess the overall the burden of mental health disorders. ${ }^{35}$ Two studies did not provide information on the instruments used for psychological assessment. ${ }^{36} 38$

\section{Study quality assessment and risk of bias}

Studies varied in quality but the majority received a rating of 'fair' quality. Only one study received a rating of 'good' quality, ${ }^{27}$ nine studies received a rating of 'fair' quality ${ }^{24-26283031333537}$ and six studies received a rating of 'poor' quality. ${ }^{79} 32343638$ Lack of sample size justification, limited assessment of confounding factors (lifetime traumatic events in particular) and lack of outcome stratification based on FGM/C type were the most common limitations. Moreover, the majority of studies did not report on the participation rate of individuals eligible for the study or whether outcome assessors were blinded to the exposure status of participants. We present the detailed quality assessment of each study in online supplementary file 2.

Among the three types of risk of bias we assessed, studies reported the highest risk of bias in exposure/ outcome relationship measurement (eight studies) followed by comparability (four studies), then selection risk of bias (two studies). A rating of 'unclear risk' was given to 11 studies when assessing selection risk of bias, 10 studies when assessing comparability risk of bias and 7 studies when assessing exposure/outcome relationship measurement risk of bias. We present the detailed risk of bias assessment of each study in figure 2 .

\section{Exposure to lifetime traumatic events}

Lifetime traumatic events can confound reported mental health outcomes. ${ }^{39}$ Yet, only four studies ${ }^{725} 2729$ explicitly reported on lifetime traumatic events when examining the association between $\mathrm{FGM} / \mathrm{C}$ and adverse mental health outcomes. Three studies ${ }^{72529}$ used 'lifetime traumatic events' as a demographic variable of study participants. Only one study ${ }^{27}$ identified 'lifetime traumatic events' as a variable predictive of adverse mental health outcomes incorporated in a regression model.

\section{Overall study results}

Fourteen out of the 16 studies reported an association between FGM/C and at least 1 adverse mental health outcome ${ }^{724-3537}$; five of these studies explicitly noted that the results were not statistically significant for all $^{25} 2931$ or some outcomes. ${ }^{32}{ }^{34}$ Of the remaining two studies, one study $^{36}$ concluded that there was no association between FGM/C and adverse mental health outcomes and the other study ${ }^{38}$ did not provide reportable results.

When stratified by study design, 11 studies $^{724-2729-32} 3435$ alsoassessed the burden of adverse mental health outcomes among a comparison group (control group). In eight of these studies, ${ }^{72426} 2730323435$ there was a higher burden of adverse mental health outcomes among women who underwent FGM/C compared with the control group. In 


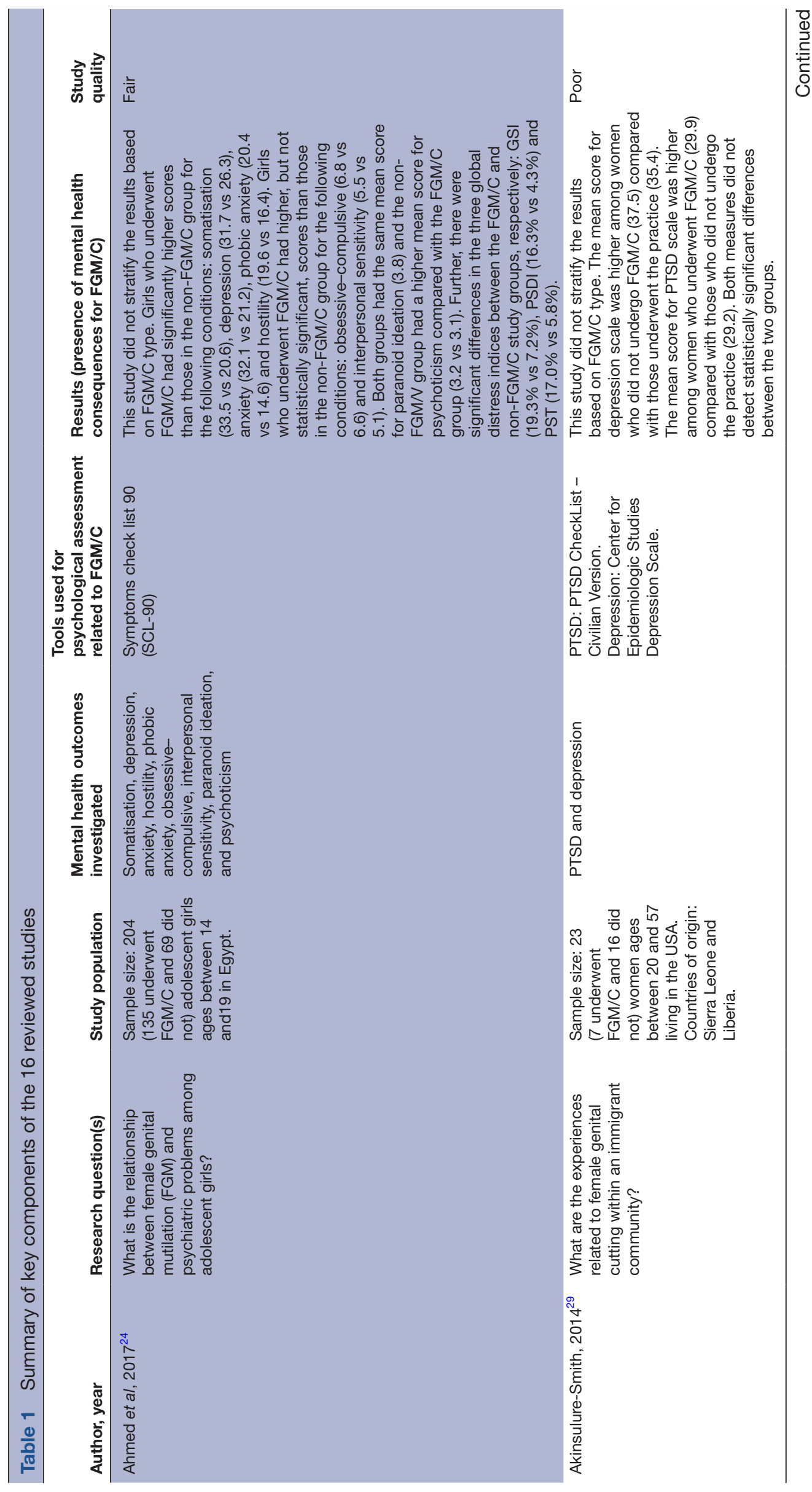




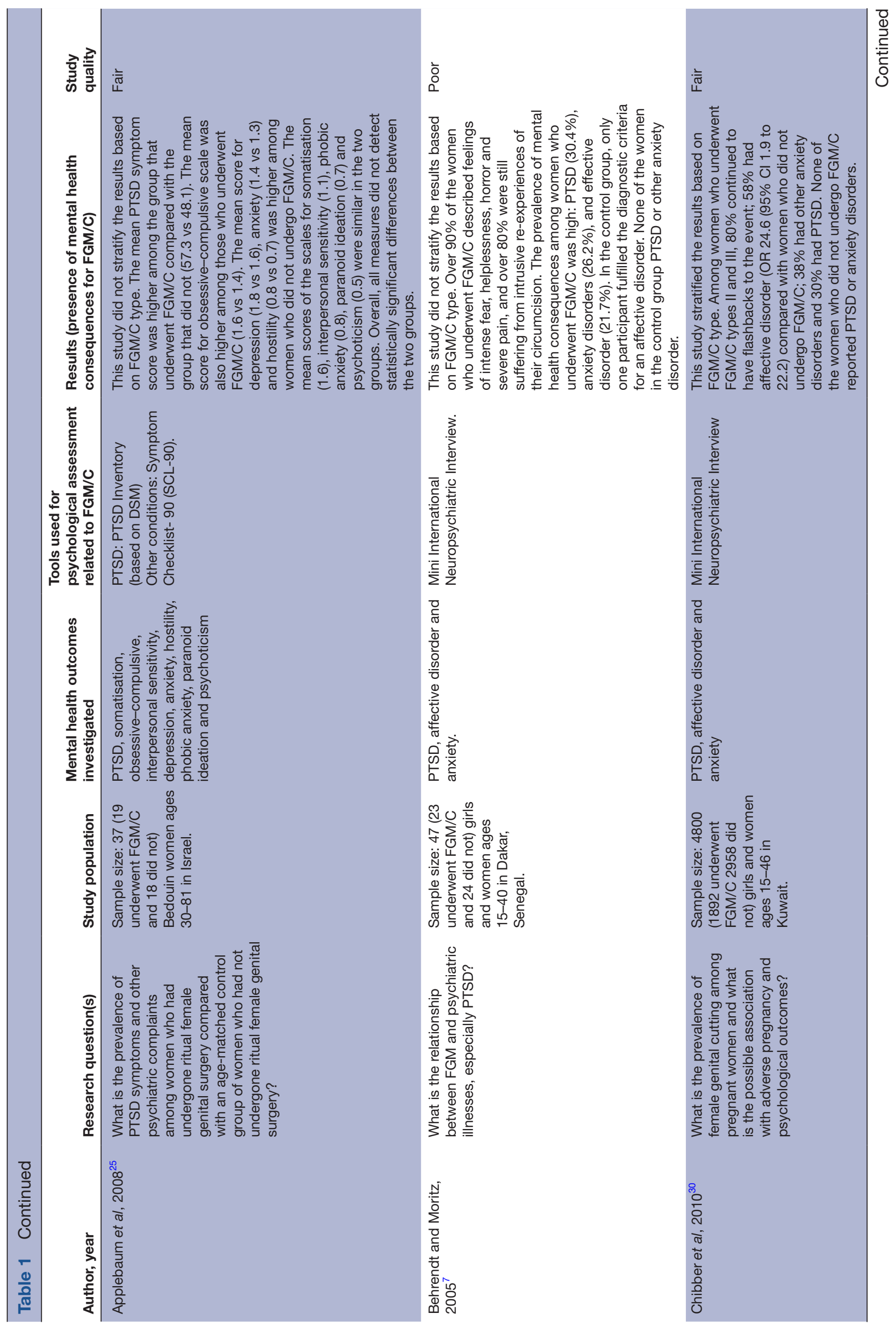




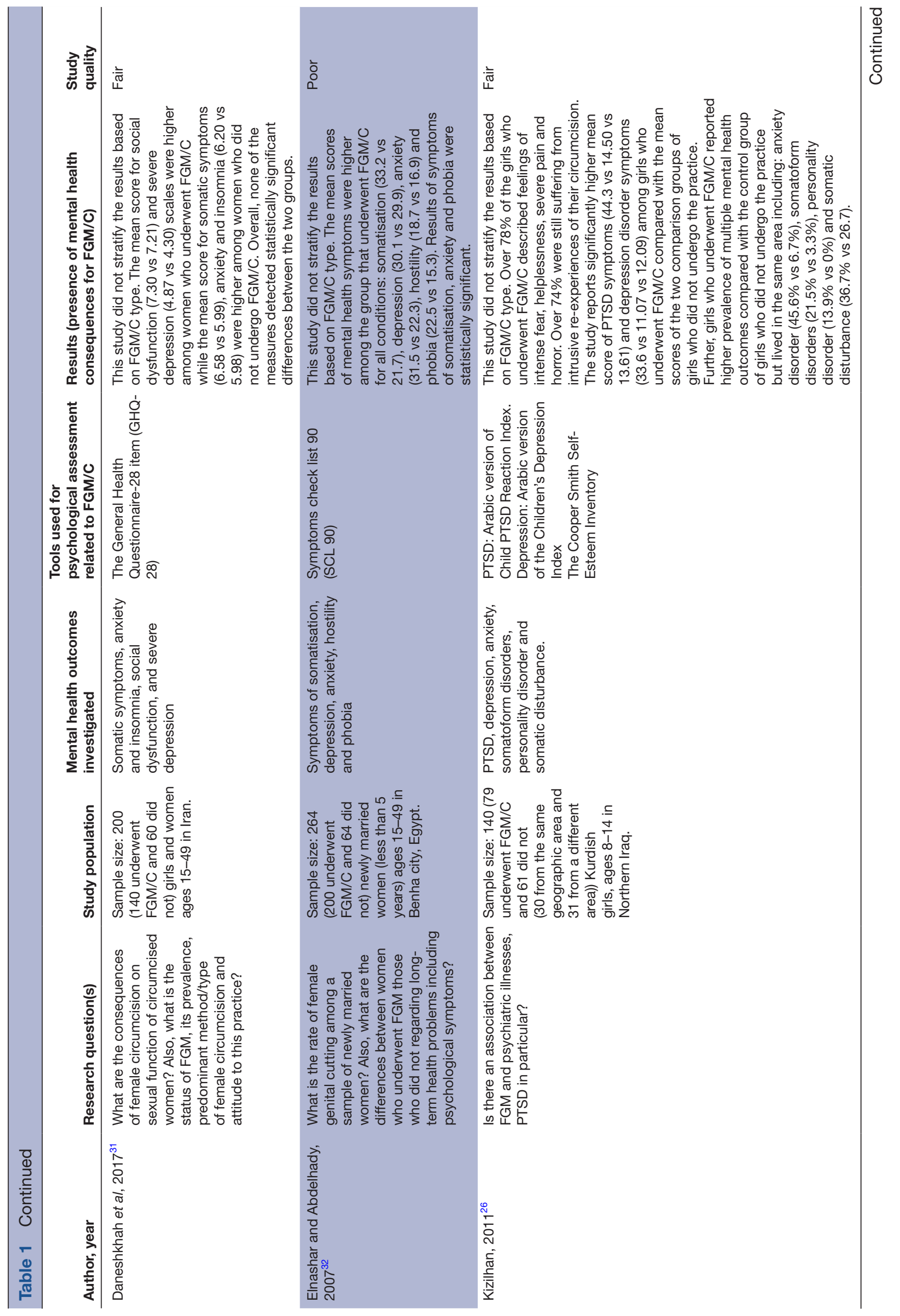




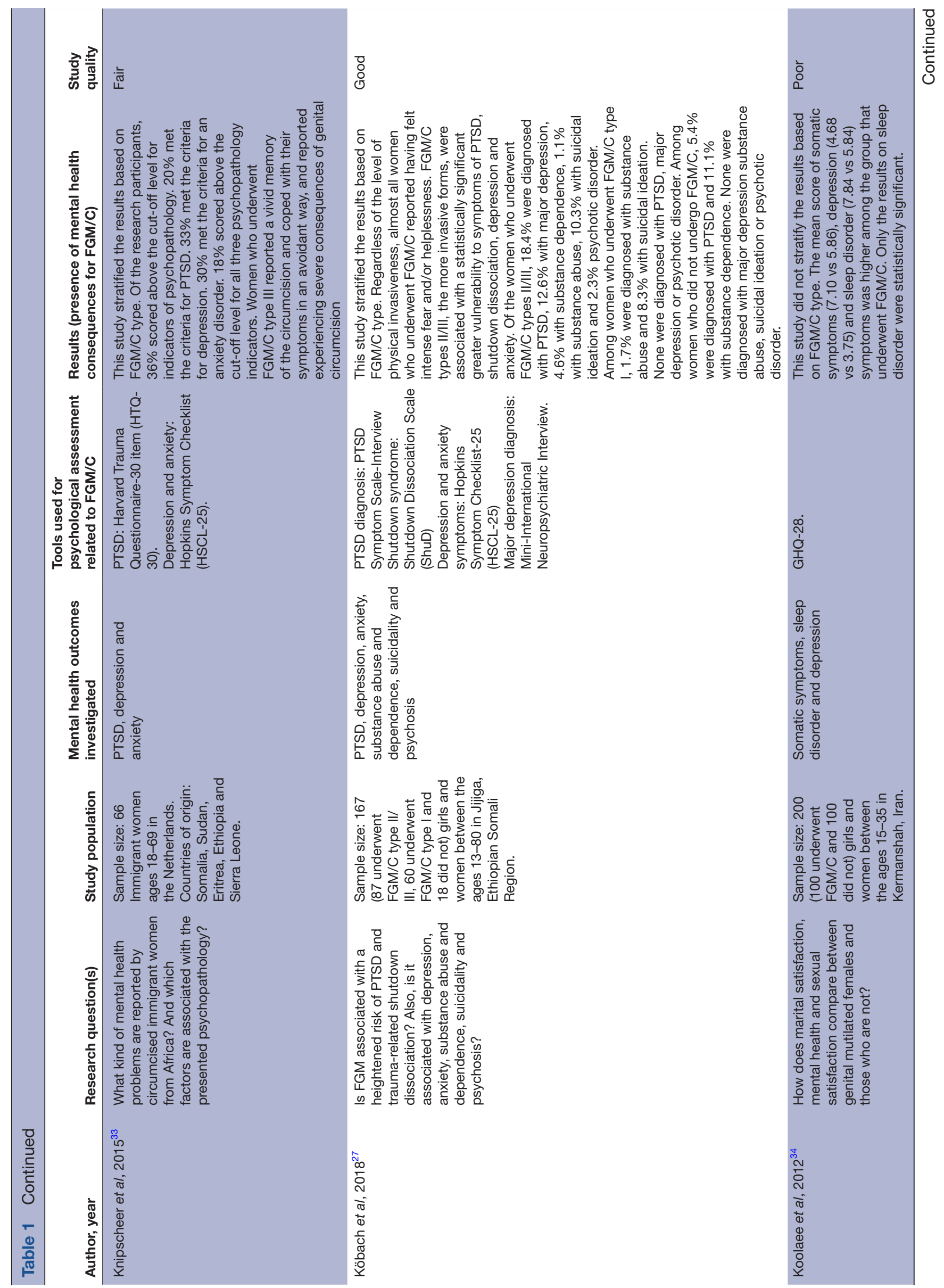




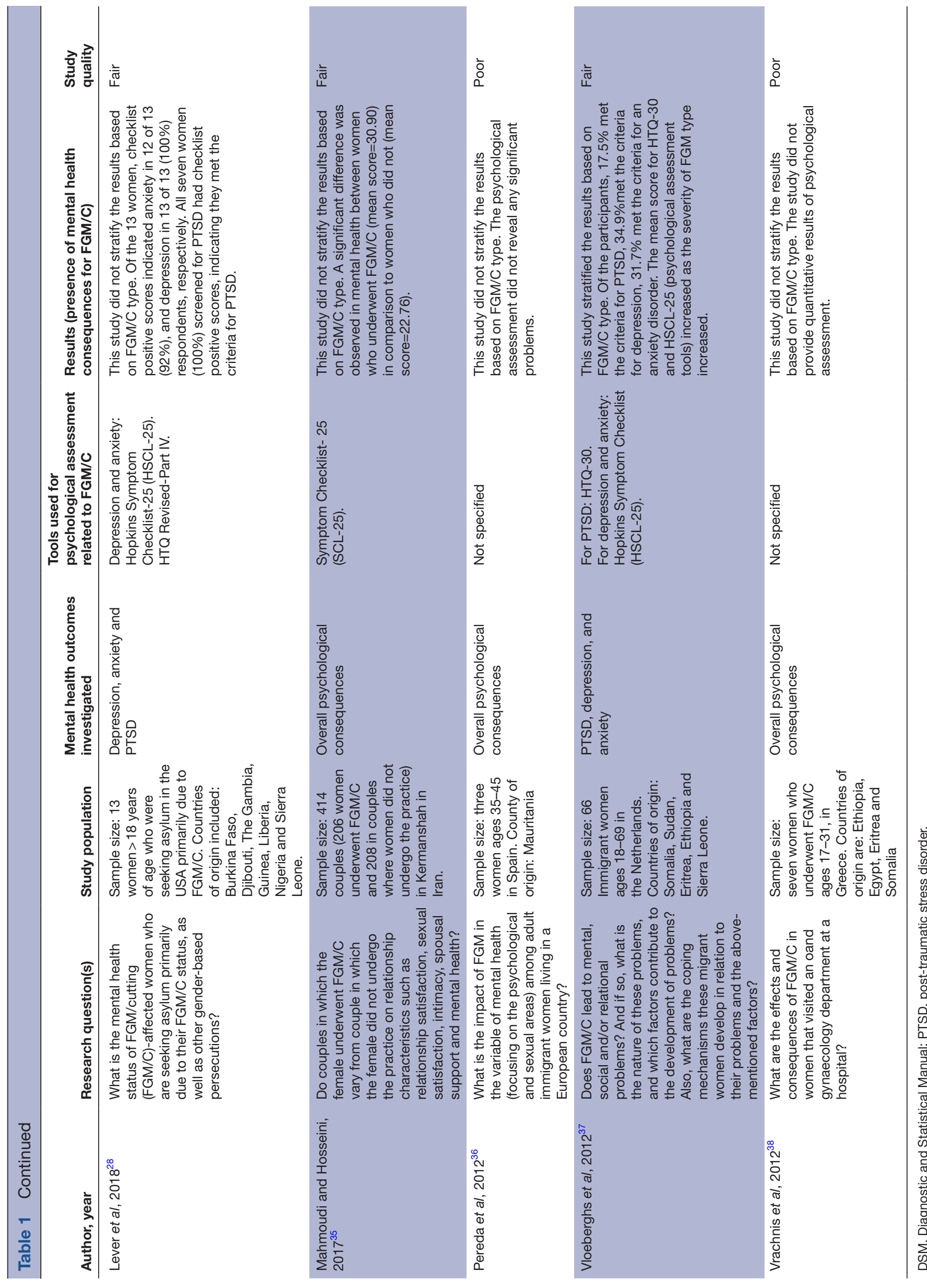




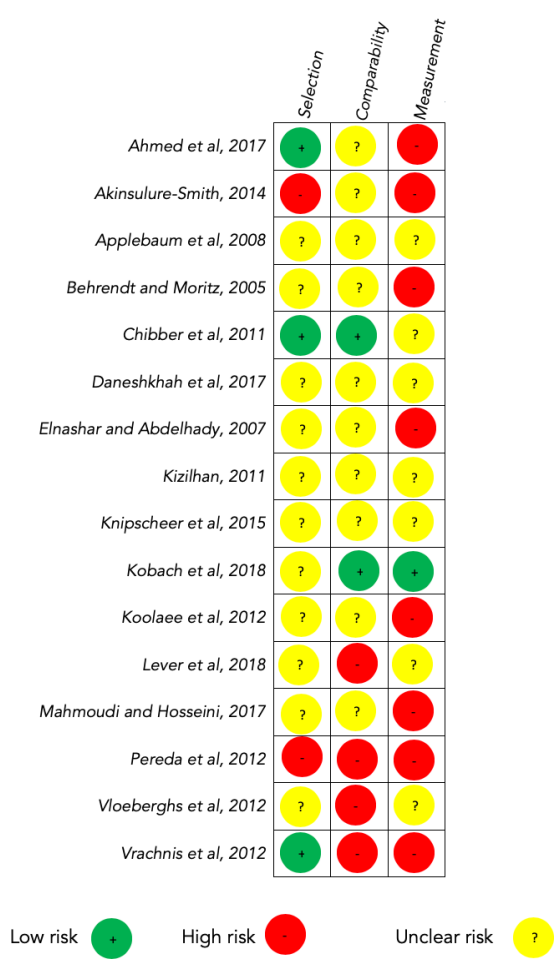

Figure 2 Reviewers' judgement about risk of bias for each item across included studies.

the remaining three studies ${ }^{25} 2931$ that assessed a control group, the results were mixed, that is, some of adverse mental health outcomes measured were higher among the group that did not undergo FGM/C. Another five studies $^{28} 33$ 36-38 did not use a control group. Among these, three studies ${ }^{28337}$ reported an association between FGM/C and adverse mental health outcomes.

\section{Study results stratified by mental health outcome}

As shown in figure 3, results differed depending on the mental health outcome assessed. Of the 11 studies that assessed depression as an outcome, three studies ${ }^{29} 3234$ received a rating of 'poor' methodological quality. Six

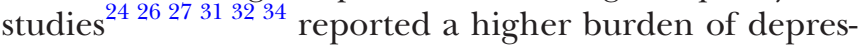
sion among women who underwent FGM/C compared

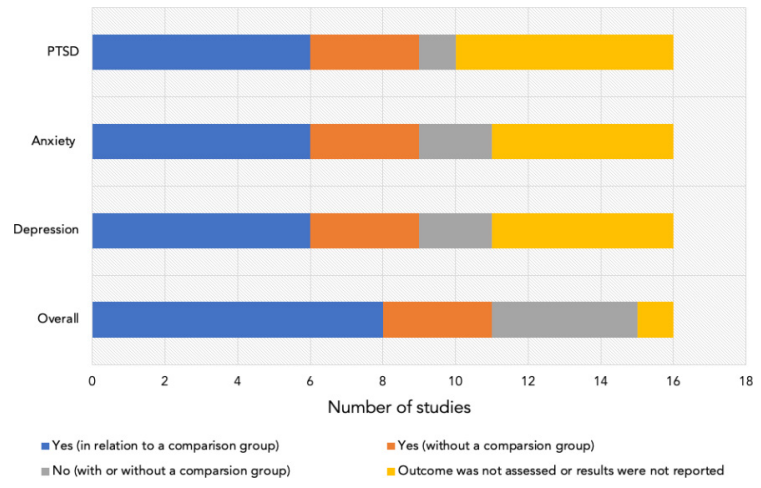

Figure 3 Overview of studies examining the association between FGM/C and adverse mental health outcomes. FGM/C, female genital mutilation/cutting; PTSD, posttraumatic stress disorder. with the control group of women who did not undergo FGM/C; two of these studies ${ }^{31} 32$ explicitly noted that the results were not statistically significant. Conversely, two studies ${ }^{25} 29$ reported a higher burden of depression among women who did not undergo $\mathrm{FGM} / \mathrm{C}$; both studies explicitly noted that the results were not statistically significant. Three studies ${ }^{28} 3337$ that only assessed women who underwent $\mathrm{FGM} / \mathrm{C}$ - that is, no control group-reported a high burden of depression among participants.

Among the 11 studies that assessed anxiety as an outcome, two studies ${ }^{72}$ received a rating of 'poor' methodological quality. Six studies ${ }^{72426273032}$ reported a higher burden of anxiety among women who underwent $\mathrm{FGM} / \mathrm{C}$ compared with the control group of women who did not undergo FGM/C. Conversely, two studies $^{25}{ }^{31}$ reported a higher burden of anxiety among women who did not undergo FGM/C; both studies noted that their results were not statistically significant. Three studies ${ }^{28} 3337$ that only assessed women who underwent FGM/C-no control group-reported a high burden of anxiety among participants; one of these studies ${ }^{33}$ explicitly noted that the results were not statistically significant.

Of the 10 studies that assessed PTSD as an outcome, one study ${ }^{7}$ received a rating of 'poor' methodological quality. Six studies ${ }^{725-27} 293033$ reported a higher burden of PTSD among women who underwent FGM/C compared with the control group of women who did not undergo FGM/C; among these, two studies ${ }^{25} 29$ noted that the results were not statistically significant. Conversely, one study ${ }^{31}$ reported a higher burden of PTSD among women who did not undergo FGM/C; the study explicitly noted that the results were not statistically significant. Three studies $^{28} 3337$ that only assessed women who underwent FGM/C - no control group-reported a high burden of PTSD among participants.

Other notable adverse mental health outcomes assessed included somatic symptoms (six studies ${ }^{724} 263032$ 34; all reported an association), overall affective disorder (two studies $^{730}$; both reported an association) and overall psychological consequences (three studies ${ }^{35}{ }^{36}{ }^{38}$; one reported an association ${ }^{35}$ ).

\section{Study results stratified by geographical location}

Of the 10 studies conducted at the participants' country of origin, three studies ${ }^{72} 34$ received a rating of 'poor' methodological quality. Eight of the 10

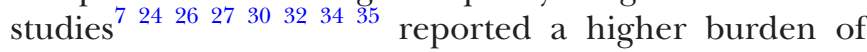
adverse mental health outcomes among women who underwent FGM/C compared with the control group of women who did not undergo FGM/C. Conversely, two studies ${ }^{25} 31$ reported mixed results, that is, some outcomes were higher among the group that did not undergo FGM/C.

Of the six studies that targeted migrant women, three studies $^{29} 3638$ received a rating of 'poor' methodological quality. One study ${ }^{29}$ that compared adverse mental health outcomes between women who underwent FGM/C and 
women who did not undergo FGM/C reported mixed results. Three studies ${ }^{2833}$ that only assessed women who underwent FGM/C-no control group-reported a high burden of adverse mental health outcomes among participants. One study ${ }^{36}$ without a control group reported a lack of association between FGM/C and adverse mental health outcomes and another study ${ }^{38}$ did not provide reportable results.

\section{Study results stratified by FGM/C type}

Four studies $^{27} 303337$ investigated whether FGM/C type (severity) affected the severity of adverse mental health outcomes. All four studies reported a correlation between the severity of FGM/C and the severity of adverse mental health outcomes. FGM/C type III (the most severe form) had the highest association with adverse mental health outcomes.

\section{DISCUSSION}

In a comprehensive review of the literature about the relation between FGM/C and adverse mental health outcome, we found that of the 16 studies included, 14 reported an association between $\mathrm{FGM} / \mathrm{C}$ and at least 1 adverse mental health outcome. The studies that examined specific mental health outcomes consistently reported an association between FGM/C and that particular outcome. The four studies that stratified their results by FGM/C type found an association between the severity of FGM/C and the severity adverse mental health outcomes. Importantly, our review found that of the included studies only one received a rating of 'good' methodological quality. Further, the majority of studies reported 'high risk of bias' or 'unclear risk' in one or more of the categories used to assess risk of bias.

Our findings are consistent with results of prior smaller reviews. For example, the review by Berg et al (included four studies), reported an association between FGM/C and adverse mental health outcomes. The same review highlighted the lack of rigour in study design and methods in included studies (all studies received a rating of 'moderate' or 'low' quality).${ }^{14}$ In their literature review on the long-term health consequences of FGM/C, Reisela and Creighton concluded that the FGM/C led to longterm adverse psychological outcomes (based on three studies). ${ }^{16}$ Our review adds to the literature through providing a more comprehensive overview of existing research on adverse mental health outcomes linked to FGM/C. Further, we provide a quality assessment for existing literature on the subject.

This review is not without limitations. First, like all systematic reviews, our review is subject to publication bias. It is possible that studies that did not show an association with mental health outcomes were not published. However, the consistent presence of an association across studies-and the observation of a dose-response relationship between the severity of FGM/C and mental health outcomes in four studies-mitigates the concern that what we are seeing spurious findings due to publication bias. Second, all the studies included in our review are cross-sectional in nature, with a small sample size, and many do not account for confounding factors; lifetime traumatic events in particular. It is, therefore, difficult, from these studies, to isolate causality only to FGM/C and it is not implausible that the observed mental health consequences are attributable to a host of concomitant conditions that disadvantage the women studied. Third, the quality assessment tools we used, while designed for observational studies in general, may be limited when assessing cross-sectional studies. This limitation, however, is more reflective of the lack of proper tools to assess cross-sectional studies in general. Finally, due to the heterogeneity in the psychosocial assessment tools used by the studies, and the low quality of included studies, it was not possible to conduct a quantitative meta-analysis of the results. It is worth noting that these limitations highlight the need to invest in quality longitudinal research on the adverse mental health consequences of FGM/C.

\section{CONCLUSION}

While there is a large body of literature on the physical effects of FGM/C, there is little quantitatively measuring the mental health consequences of the practice. This review provides a comprehensive summary of the existing literature on the adverse mental health consequences of $\mathrm{FGM} / \mathrm{C}$. The observation that $\mathrm{FGM} / \mathrm{C}$ is associated with adverse mental health outcomes should not be surprising. There is abundant evidence that traumatic event experiences are associated with adverse mental health outcomes over the life course. ${ }^{40} \mathrm{FGM} / \mathrm{C}$, especially severe forms, can be a traumatic experience through deliberating inflicting of harm on girls, often without anaesthesia, at a particularly sensitive life course period. This review should set to rest, once and for all, the misconception that the cultural normalisation of FGM/C somehow minimises the adverse mental health consequences associated with this practice. ${ }^{15}$ This review shows that, in addition to the physical consequence of this practice, it is also associated with poor mental health outcomes that may accompany women throughout their lives.

Importantly, our review demonstrates the need for further, better quality, research on the topic. Based on our review, future research should aim to incorporate the following criteria to improve the methodological quality of evidence on the topic: 1) improve and standardise the psychological tools necessary to assess the association between FGM/C and adverse health outcomes; 2) independently investigate the board range of potential adverse mental health outcomes that may be associated with undergoing FGM/C; 3) stratify reported outcomes based on FGM/C type; 4) address and control for potential confounding, lifetime traumatic events in particular; and 5) use longitudinal study designs to document the 
full scope of the mental health consequences of FGM/C over time.

\section{Twitter@SalmaMHAbdalla}

Contributors SMA concieved the design of the study. SMA led the analysis process with support and supervision from SG. SMA wrote the first draft and SG commented and edited all versions of the draft. Both authors read and approved the final draft.

Funding The authors have not declared a specific grant for this research from any funding agency in the public, commercial or not-for-profit sectors.

Competing interests None declared.

Patient consent for publication Not required.

Provenance and peer review Not commissioned; externally peer reviewed.

Data availability statement № additional data are available.

Open access This is an open access article distributed in accordance with the Creative Commons Attribution Non Commercial (CC BY-NC 4.0) license, which permits others to distribute, remix, adapt, build upon this work non-commercially, and license their derivative works on different terms, provided the original work is properly cited, appropriate credit is given, any changes made indicated, and the use is non-commercial. See: http://creativecommons.org/licenses/by-nc/4.0/.

\section{REFERENCES}

1. UNICEF. Female genital mutilation, 2018. Available: https:// data.unicef.org/topic/child-protection/female-genital-mutilation/ [Accessed 26 Feb 2019].

2. Kandala N-B, Ezejimofor MC, Uthman OA, et al. Secular trends in the prevalence of female genital mutilation/cutting among girls: a systematic analysis. BMJ Glob Health 2018;3:e000549.

3. WHO. Female genital mutilation, 2018. Available: https://www. who.int/news-room/fact-sheets/detail/female-genital-mutilation [Accessed 26 Feb 2019].

4. Simpson J, Robinson K, Creighton SM, et al. Female genital mutilation: the role of health professionals in prevention assessment, and management. BMJ 2012;344:e1361.

5. WHO. Eliminating female genital mutilation: An interagency statement - OHCHR, UNAIDS, UNDP, UNECA, UNESCO, UNFPA, UNHCR, UNICEF, UNIFEM, WHO. WHO. Geneva 2018.

6. WHO. Female Genital Mutilation - Integrating the Prevention and the Management of the Health Complications into the curricula of nursing and midwifery: A Student's Manual [Internet]. Geneva, 2001. Available: https://apps.who.int/iris/bitstream/handle/10665/66857/ WHO_FCH_GWH_01.4.pdf?sequence=2 [Accessed 4 Mar 2019].

7. Behrendt A, Moritz S. Posttraumatic Stress Disorder and Memory Problems After Female Genital Mutilation. Am J Psychiatry 2005;162:1000-2

8. WHO. Classification of female genital mutilation. World Health Organization, 2007.

9. Leye E, Deblonde J, García-Añón J, et al. An analysis of the implementation of laws with regard to female genital mutilation in Europe. Crime Law Soc Change 2007;47:1-31.

10. Berg RC, Odgaard-Jensen J, Fretheim A, et al. An updated systematic review and meta-analysis of the obstetric consequences of female genital mutilation/cutting. Obstet Gynecol Int 2014;2014:1:1-8.

11. Banks E, Meirik O, Farley T, et al. Female genital mutilation and obstetric outcome: WHO collaborative prospective study in six African countries. Lancet 2006;367:1835-41.

12. Serour GI. Medicalization of female genital mutilation/cutting. African Journal of Urology 2013;19:145-9.

13. Berg RC, Underland V, Odgaard-Jensen J, et al. Effects of female genital cutting on physical health outcomes: a systematic review and meta-analysis. BMJ Open 2014;4:e006316.

14. Berg RC, Denison E, Psychological FA. Social and Sexual Consequences of Female Genital Mutilation/Cutting (FGM/C): A Systematic Review of Quantitative Studies [Internet]. Norwegian Knowledge Centre for the Health Services. Knowledge Centre for the Health Services at The Norwegian Institute of Public Health 2010 (cited 2019 Feb 26)

15. Mulongo P, McAndrew S, Hollins Martin C. Crossing borders: Discussing the evidence relating to the mental health needs of women exposed to female genital mutilation. Int $\mathrm{J}$ Ment Health Nurs 2014;23:296-305.

16. Reisel D, Creighton SM. Long term health consequences of Female Genital Mutilation (FGM). Maturitas 2015;80:48-51.

17. Home - PubMed [Internet]. NCBI, 2019. Available: https://www.ncbi. nlm.nih.gov/pubmed [Accessed 19 Jan 2019].

18. Embase. Embase, 2019. Available: https://www.embase.com/\# search [Accessed 27 Feb 2019].

19. Web of Science. Web of Science. Available: http://login webofknowledge.com/error/Error?Error=IPError\&Pathlnfo=\%2F\& RouterURL=http\%3A\%2F\%2Fwww.webofknowledge.com\%2F\& Domain=.webofknowledge.com\&Src=IP\&Alias=WOK5 [Accessed 19 Jan 2019].

20. PsycINFO. PsycINFO | EBSCO [Internet], 2019. Available: https:// www.ebsco.com/products/research-databases/psycinfo [Accessed 27 Feb 2019]

21. NIH. Study Quality Assessment Tool for Observational Cohort and Cross-Sectional Studies [Internet], 2019. Available: https:// www.nhlbi.nih.gov/health-topics/study-quality-assessment-tools [Accessed 25 Feb 2019].

22. Allen LN, Pullar J, Wickramasinghe KK, et al. Evaluation of research on interventions aligned to WHO 'Best Buys' for NCDs in lowincome and lower-middle-income countries: a systematic review from 1990 to 2015. BMJ Glob Health 2018;3:e000535.

23. Wells G, Shea B, O'Connell D, et al. The Newcastle-Ottawa Scale (NOS) for assessing the quality of nonrandomised studies in metaanalyses [Internet] 2000

24. Ahmed MR, Shaaban MM, Meky HK, et al. Psychological impact of female genital mutilation among adolescent Egyptian girls: a cross-sectional study. The European Journal of Contraception \& Reproductive Health Care 2017;22:280-5.

25. Applebaum J, Cohen H, Matar M, et al. Symptoms of Posttraumatic Stress Disorder After Ritual Female Genital Surgery Among Bedouin in Israel. Prim. Care Companion J. Clin. Psychiatry 2008;10:453-6.

26. Kizilhan JI. Impact of psychological disorders after female genital mutilation among Kurdish girls in northern Iraq. Eur J Psychiatry 2011;25(2):92-100.

27. Köbach A, Ruf-Leuschner M, Elbert T. Psychopathological sequelae of female genital mutilation and their neuroendocrinological associations. BMC Psychiatry 2018;18:187

28. Lever H, Ottenheimer D, Atkinson HG, et al. Depression, Anxiety, Post-traumatic Stress Disorder and a History of Pervasive GenderBased Violence Among Women Asylum Seekers Who Have Undergone Female Genital Mutilation/Cutting: A Retrospective Case Review. J Immigr Minor Heal 2018.

29. Akinsulure-Smith AM. Exploring female genital cutting among West African immigrants. J Immigrant Minority Health 2014;16:559-61.

30. Chibber R, El-saleh E, El harmi J. Female circumcision: obstetrical and psychological sequelae continues unabated in the 21 st century. The Journal of Maternal-Fetal \& Neonatal Medicine 2011;24:833-6.

31. Daneshkhah F, Allahverdipour H, Jahangiri L, et al. Mental Well-being and Quality of Life among Kurdish Circumcised Women in Iran. Iran $J$ Public Health 2017:46:1265-74.

32. Elnashar A, Abdelhady R. The impact of female genital cutting on health of newly married women. International Journal of Gynecology \& Obstetrics 2007:97:238-44

33. Knipscheer J, Vloeberghs E, van $\operatorname{der}$ Kwaak A, et al. Mental health problems associated with female genital mutilation. BJPsych Bulletin 2015;39:273-7.

34. Koolaee AK, Pourebrahim T, Mohammadmoradi B, et al. The comparison of marital satisfaction and mental health in genital mutilated females and non-genital mutilated females. Int $J$ high risk Behav Addict [Internet] 2012;1:115-20.

35. Mahmoudi O, Hosseini E. Psychosexual complications of female genital mutilation for couples: A comparative study. J Kermanshah Univ Med Sci 2017;20:135-40.

36. Pereda N, Arch M, Pérez-González A. A case study perspective on psychological outcomes after female genital mutilation. J Obstet Gynaecol 2012;32:560-5.

37. Vloeberghs E, van der Kwaak A, Knipscheer J, et al. Coping and chronic psychosocial consequences of female genital mutilation in the Netherlands. Ethn Health 2012;17:677-95.

38. Vrachnis N, Salakos N, lavazzo C, et al. Female genital mutilation in Greece. Clin Exp Obstet Gynecol 2012;39:346-50.

39. Turner RJ, Lloyd DA. Lifetime traumas and mental health: the significance of cumulative adversity. J Health Soc Behav 1995;36:360-76.

40. Fink DS, Galea S. Life course epidemiology of trauma and related psychopathology in civilian populations. Curr Psychiatry Rep 2015;17:31. 